\title{
THE DETERMINANTS OF LEAD AND CADMIUM BLOOD LEVELS FOR PRESCHOOL CHILDREN FROM INDUSTRIALLY CONTAMINATED SITES IN POLAND
}

\author{
MAŁGORZATA KOWALSKA ${ }^{1}$, ELŻBIETA KULKA ${ }^{2}$, WANDA JAROSZ ${ }^{2}$, and MICHAŁ KOWALSKI ${ }^{3}$ \\ ${ }^{1}$ Medical University of Silesia, Katowice, Poland \\ School of Medicine, Department of Epidemiology \\ ${ }^{2}$ Institute for Ecology of Industrial Areas, Katowice, Poland \\ ${ }^{3}$ Silesian University of Technology, Gliwice, Poland \\ Department of Air Protection, Faculty of Energy and Environmental Engineering
}

\begin{abstract}
Objectives: Industrially contaminated sites (ICS) represent an important public health issue in European countries. The Silesian Voivodeship, the region located in the southern part of Poland, the historical center of industry, has many sites that meet ICS criteria. Most of them are landfills containing lead, cadmium and zinc. Material and Methods: The aim of the study has been to evaluate determinants of lead and cadmium blood levels for preschool children living in the vicinity of selected environmental hazards in Piekary Sląskie, the city located in the region of Silesia. Data about exposure was obtained from the parental questionnaire and was verified by levels of biomarkers in children's blood. Finally, 678 preschool children were studied. Results: Obtained results have confirmed that the statistically significant higher level of lead in blood has been revealed in the case of younger children whose fathers have a higher level of education and whose mothers smoke cigarettes at home, as well as for those living in the vicinity of any environmental hazard. In the case of cadmium, a higher level of the biomarker has been reported for older children who rather do not live close to any environmental hazard. We have recognized $30 \%$ of children with blood lead level $(\mathrm{PbB})$ exceeding $2 \mu \mathrm{g} / \mathrm{dl}$ and $0.8 \%$ of children with blood cadmium level $(\mathrm{CdB})$ exceeding the reference value $(0.5 \mu \mathrm{g} / \mathrm{l})$. Conclusions: Own observation has confirmed that preschool children living in Piekary Śląskie are still exposed to heavy metals existing in environment. The source of the higher level in blood is not only the hazardous vicinity in the place of residence but also well-known factors associated with the age of children, parental life style and educational background. The parental questionnaire could be useful to identify potential determinants of exposure to lead and cadmium, however exposure must be verified by measurement of a proper biomarker. Int J Occup Med Environ Health 2018;31(3):351-359
\end{abstract}

Key words:

Exposure, Cadmium, Lead, Preschool children, ICS, Parental questionnaire

Funding: project was supported by the National Fund for Environmental Protection and Water Management grant No. 966/2012/Wn-50/EE-PO/D. Grant manager: Elżbieta Kulka, Ph.D.

Received: November 9, 2016. Accepted: February 13, 2017.

Corresponding author: M. Kowalska, Medical University of Silesia, School of Medicine, Department of Epidemiology, Medyków 8, 40-752 Katowice, Poland (e-mail: mkowalska@sum.edu.pl). 


\section{INTRODUCTION}

Industrially contaminated sites (ICS) represent an important public health issue in European countries. The reason for this statement is the high level of hazards and serious health problems expected for the population living in their vicinity [1]. In 2015 the European Cooperation in Science and Technology (COST) Action IS1408 - the project supported by the European Union (EU) Framework Programme Horizon 2020 was launched to promote international cooperation for: developing guidelines on strategies for environmental health studies in contaminated regions (including epidemiology, exposure assessment, toxicology, human biomonitoring, environmental monitoring and modelling), developing communication strategies, and implementing health assessment for particular groups of population (e.g., children) [2]. During the working groups meetings experts focused on developing the framework assessing the relationship between ICS and potential health disorders among inhabitants of the COST member countries. One of working groups (WG2) prepared recommendations and possibilities for methods and tools for exposure assessment according to available bibliography and case studies [2].

It is well documented that the place of residence is essential for proper children growth. Living in the polluted area could result in diminished intelligence, behavioral disorders, failure at school, delinquency and diminished achievement [3]. While in Poland, there is no definition of ICS and any registry of such sites doesn't exist, either, however there is a bulk of evidence that the Silesian Voivodeship is the most degraded region in the country. This region was the most exploited by industry, there are located landfills with heavy metals. Piekary Śląskie is one of the most polluted city of the Silesian region, about $1 / 4$ of its area is occupied by a large landfill containing lead, cadmium and zinc. It is well known that lead is a significant child hazard, a bulk of epidemiological evidence has confirmed that even small amount may cause serious health consequences [4]. In Poland usage of lead has sharply de- creased in the past 2 decades and published data shows clear significant decrease in average blood lead level in the case of children during the years 1991-2009 [5]. However, a higher value of blood lead level $(\mathrm{PbB})$ (higher than $2 \mu \mathrm{g} / \mathrm{dl}$, which requires an educational intervention and reassessment of lead exposure [6]) is observed in the case of children living in the most industrialized regions of Poland, especially in those located in the proximity of sources of emission or degraded sites.

The aim of the study is to evaluate the relationship between lead and cadmium concentration in children's blood and their places of residence in Piekary Śląskie, the Silesian Voivodeship, Poland. The general question is to assess the validity of use of information provided by parents for the purpose of identification of children's high exposure to lead and cadmium.

\section{MATERIAL AND METHODS}

The study was performed in Piekary Śląskie, the city located in the Silesian Voivodeship (the southern part of Poland), inhabited by 2196 children aged 3-7 years old (data was obtained from the Education Department of the Municipal Office in Piekary Śląskie on February 20, 2012). Most of them $(\mathrm{N}=1752,79.8 \%)$ are pupils of 15 kindergartens located in the city.

Available data describing lead and cadmium concentration measured in 2006 in the surface layer of soil in Piekary Śląskie suggested that the highest concentration was recognized in gardens. The average geometric mean value was 569.7 (range: 201-2159) $\mathrm{mg} / \mathrm{kg}$ for lead and 16.9 (range: $5.52-58.6$ ) mg/kg for cadmium, measured levels in playgrounds were twice lower $(293.1 \mathrm{mg} / \mathrm{kg}$ and $8.8 \mathrm{mg} / \mathrm{kg}$ ) for lead and cadmium, respectively [7]. Due to the high stability of lead and cadmium in the soil and the lack of corrective action in the city, it was assumed that the concentrations of both metals would remain high. In order to assess the relationship between the place of residence and the measured level of lead or cadmium in blood, 
we used the data obtained from the cross-sectional study conducted in 2013 among preschool children aged 3-6 years old, pupils of all nurseries located in Piekary Śląskie. First, in order to assess the exposure, samples of venous blood were collected from spring to autumn. After obtaining the parental agreement to study, $1 \mathrm{ml}$ of blood was taken from each child using lead-free vacutainer tubes. Measurements of biomarkers were based on standard procedures [7,8]: blood lead level $(\mathrm{PbB})$ and blood cadmium level $(\mathrm{CdB})$ were detected by the atomic absorption spectrophotometry (ICE 3000 Thermo Fisher, USA).

Data about exposure was also obtained from the parental questionnaire which included questions concerning potential sources of heavy metals in the environment as well as socio-economic issues. Following variables were taken into account: time spent outdoor in winter and summer season according to the median value $((\mathrm{Me})=1.5 \mathrm{~h}$ and $\mathrm{Me}=4 \mathrm{~h}$, in winter and summer, respectively), living close to particular environmental hazard sources (yes/no), parental occupational contact with heavy metals (yes/no), parental tobacco smoking at home (yes/no), and parental level of education (lower $=$ primary, and vocational/higher $=$ secondary and higher). Additionally, it was attempted to assess whether the fact of residence in various districts would affect the value of measured concentrations of heavy metals in children's blood. Finally, 678 preschool children $(38.7 \%$ of the total number of kindergarten pupils in Piekary Śląskie) were studied. Subjects were comparable with the general population of preschool children in terms of age and gender.

The statistical analysis was performed using Statistica 10.0 software (StatSoft, 2015). Significance of betweengroup differences for continuous variables was evaluated by means of ANOVA Kruskall-Wallis or Mann-Whitney $U$ test, respectively. Finally, the stepwise regression procedure was used for evaluating the relationship between selected independent variables and 2 dependent variables (logarithm of $\mathrm{PbB}$ and $\mathrm{CdB}$ concentration in blood). Statistical significance level was set at $\alpha=0.05$.

\section{RESULTS}

The study group included 678 children, namely 341 girls and 337 boys. Accurate data describing the place of residence and its relation to environmental pollutants was obtained for 519 children: 259 of them (37.5\%) lived in the vicinity of a busy road, 34 children (4.9\%) lived close to a gas station, 57 children (8.3\%) lived close to a car workshop, and 109 children (15.8\%) lived close to a metallurgical slag heap.

The Figure 1 presents levels of both biomarkers for subjects living in a particular district of Piekary Śląskie. Obtained results have confirmed that the highest $\mathrm{PbB}$ level has been revealed for children residing in Brzeziny Śląskie, the district where Orzeł Bialy smelter and its landfill (heap) are located. Gender has no statistically significant impact on the value of lead and cadmium biomarkers in the study group, however higher levels have been detected for boys rather than girls (the Table 1 presents geometric mean values of both biomarkers). Moreover, we have observed that the measured concentrations of both biomarkers are higher in the case of those children who spend more time playing outdoor, especially in winter time.

The Table 2 shows particular descriptive statistics of subjects according to the place of residence reported in the parental questionnaire. Gender has no statistically significant impact on the average level of both biomarkers in the total study group, however a higher concentration of lead has been detected in the case of boys rather than girls (the geometric mean of PbB: $2.54 \mu \mathrm{g} / \mathrm{dl}$ and $2.39 \mu \mathrm{g} / \mathrm{dl}$, respectively). This observation has been the same in particular subgroups of subjects defined by the place of residence, however, the level of $\mathrm{PbB}$ has been statistically significantly higher in the case of boys rather than girls living in the vicinity of a gas station $(\mathrm{p}=0.004)$. While in the case of $\mathrm{CdB}$, the geometric mean is a bit lower in the case of boys rather than girls $(0.24 \mu \mathrm{g} / \mathrm{l}$ and $0.25 \mu \mathrm{g} /$, respectively in the group as a whole), this observation has been similar for children living in the vicinity of a busy road, gas station, metallurgical heap and industrial plant. 

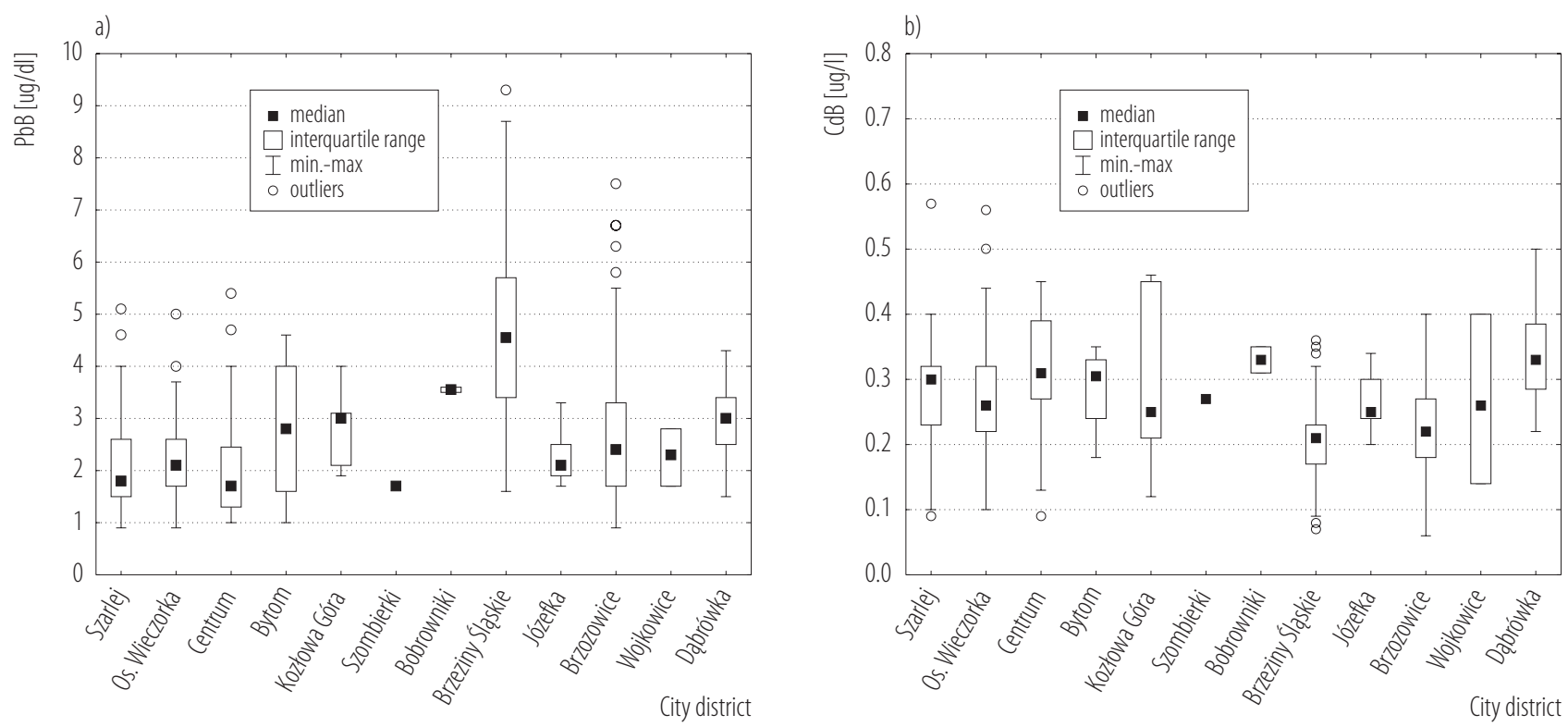

min. - minimal value; max - maximal value.

Fig. 1. Level of a) lead $(\mathrm{PbB})$ and b) cadmium $(\mathrm{CdB})$ in blood of preschool children living in the vicinity of environmental hazards in Piekary Sląskie, Poland, by city district

Results of ANOVA Kruskall-Wallis test suggest that the observed differences in biomarkers among the total group of children are statistically significant at the level $p<0.0001$ for lead and $p=0.001$ for cadmium, respectively. The highest value of $\mathrm{PbB}$ concentration has been detected for children living close to a metallurgical heap (the geometric mean is $3.89 \mu \mathrm{g} / \mathrm{dl}$ ) whereas in the case of $\mathrm{CdB}$, differences have not been so clear. In addition, there is no interaction between levels of both biomarkers in the case of children residing in the vicinity of environmental health hazards and a busy road, the detailed data is shown in the Figure 2.

A higher level of lead has been recognized in the case of younger children (Figure 3), although the observed difference has not been statistically significant in the ANOVA test $(p=0.09)$. While in the case of cadmium, the level in blood increases with age, the highest value is in the case of 7-year-old children ( $p<0.0001$ in the ANOVA test).

Table 1. Level of lead $(\mathrm{PbB})$ and cadmium $(\mathrm{CdB})$ in blood of preschool children living in the vicinity of environmental hazards in Piekary Śląskie, Poland, by gender and time spent outdoor

\begin{tabular}{|c|c|c|c|c|c|c|c|c|c|}
\hline \multirow{4}{*}{ Biomarker } & \multicolumn{9}{|c|}{ Biomarker's level in blood } \\
\hline & \multirow{2}{*}{\multicolumn{3}{|c|}{ gender }} & \multicolumn{6}{|c|}{ time spent outdoor } \\
\hline & & & & \multicolumn{3}{|c|}{ winter } & \multicolumn{3}{|c|}{ summer } \\
\hline & girls & boys & $\mathrm{p}$ & $<1.5 \mathrm{~h}$ & $\geq 1.5 \mathrm{~h}$ & $\mathrm{p}$ & $<4 \mathrm{~h}$ & $\geq 4 \mathrm{~h}$ & $\mathrm{p}$ \\
\hline $\mathrm{PbB}[\mu \mathrm{g} / \mathrm{dl}]$ & 2.39 & 2.54 & 0.08 & 2.34 & 2.51 & 0.05 & 2.34 & 2.51 & 0.04 \\
\hline $\mathrm{CdB}[\mu \mathrm{g} / \mathrm{l}]$ & 0.24 & 0.25 & 0.30 & 0.24 & 0.25 & 0.04 & 0.24 & 0.24 & 0.10 \\
\hline
\end{tabular}

$\mathrm{p}$ - results of Mann-Whitney U test. 


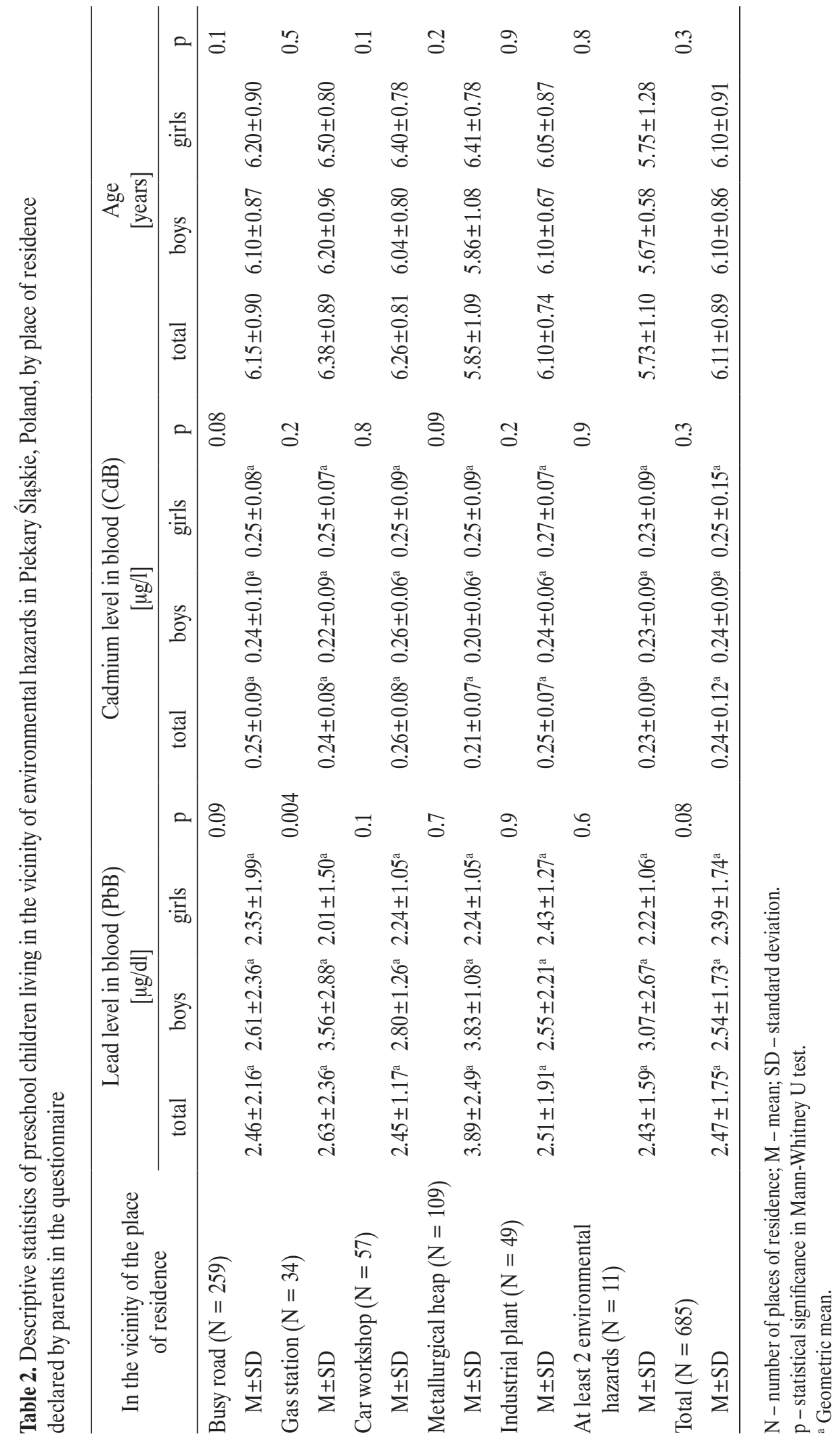


Another issue has been the evaluation of the relationship between levels of both the biomarker in children's blood and indoor environment or parental behavior declared in the questionnaire. Results of the multivariate analysis confirm that the statistically significant higher level of lead in blood has been related to younger children $(p=0.000007)$, children whose fathers have a higher level of education $(p=0.007)$ and whose mother smoke cigarettes at home $(p=0.02)$ as well as those living in the vicinity of any environmental hazard $(p<0.0000001)$. Detailed results are shown in the Table 3 .
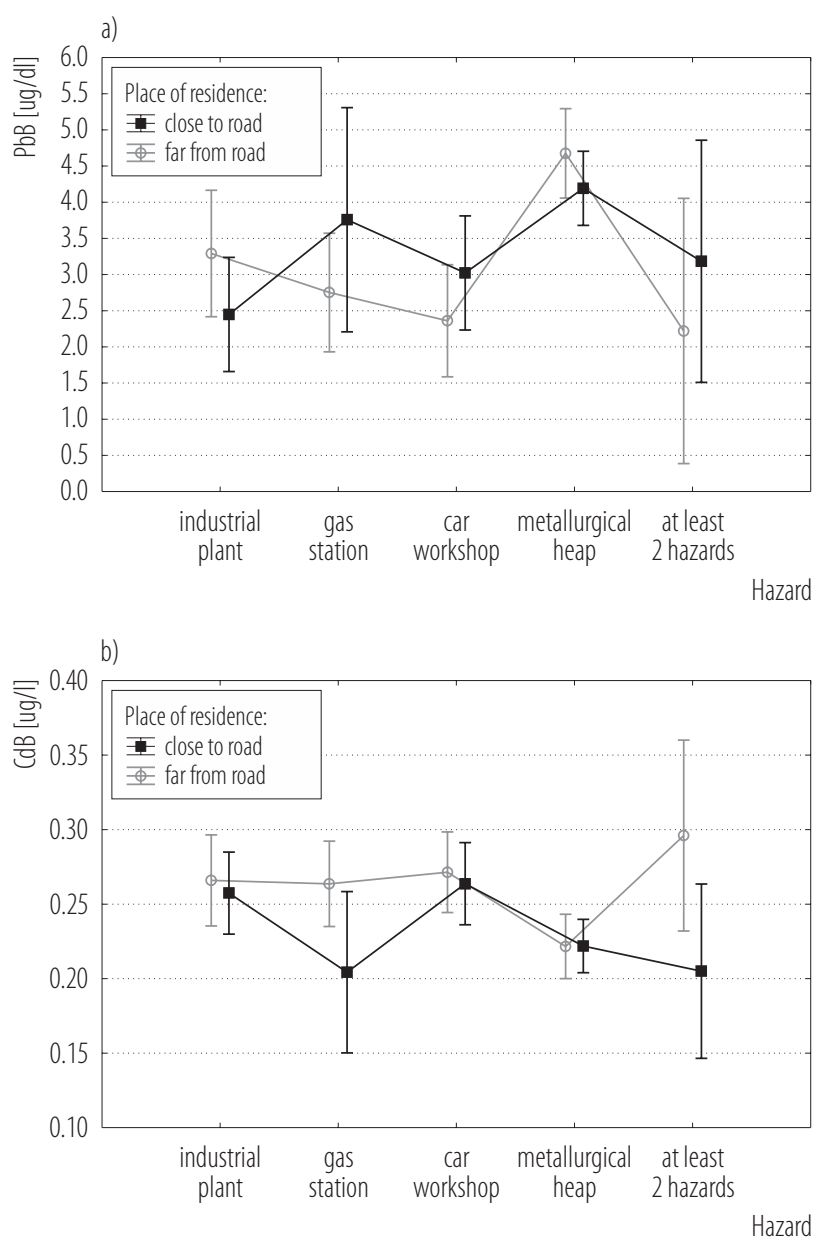

Fig. 2. Level of a) lead ( $\mathrm{PbB})$ and b) cadmium (CdB) in blood of preschool children in Piekary Śląskie, Poland, by the place of residence close to environmental hazards
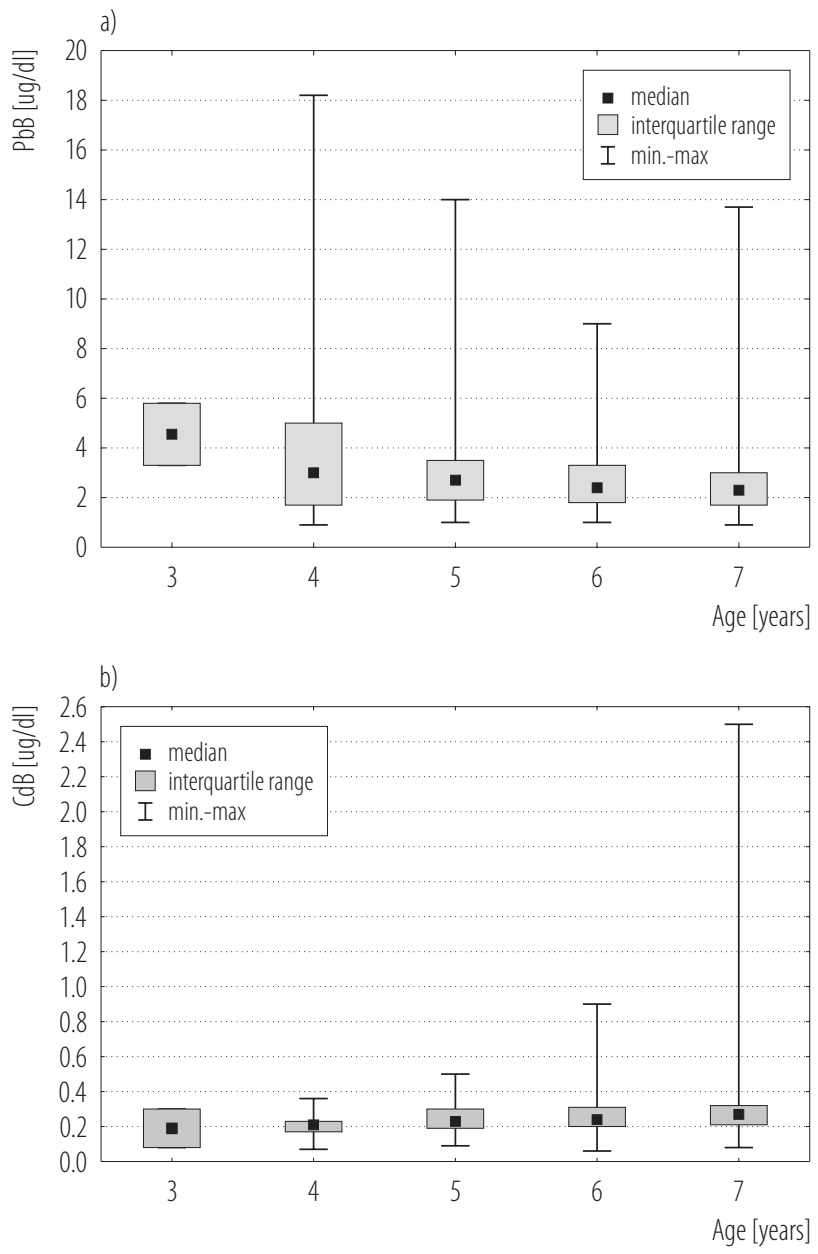

min. - minimal value; $\max$ - maximal value.

Fig. 3. Level of a) lead $(\mathrm{PbB})$ and b) cadmium $(\mathrm{CdB})$ in blood of preschool children in Piekary Śląskie, Poland, by age

In the case of cadmium, a higher level of the biomarker has been reported for older children $(p<0.0000001)$ and those not living close to any environmental hazard $(p=0.03)$, however the value of evaluated $R^{2}$ rather indicates low usefulness of the model in terms of any conclusive summary.

The percentage share of children who have exceeded the value of $10 \mu \mathrm{g} / \mathrm{dl}$ for lead has been $0.87 \%$. Detailed data suggests that children with those very high $\mathrm{PbB}$ levels in Piekary Śląskie inhabit the region in the vicinity of a smelter heap $(\mathrm{N}=3)$, live close to a gasoline station, an indus- 
Table 3. Stepwise regression for the relationship between lead $(\mathrm{PbB})$ and cadmium levels in blood $(\mathrm{CdB})$ and selected independent variables determining exposure of preschool children living in the vicinity of environmental hazards in Piekary Śląskie, Poland ${ }^{a}$

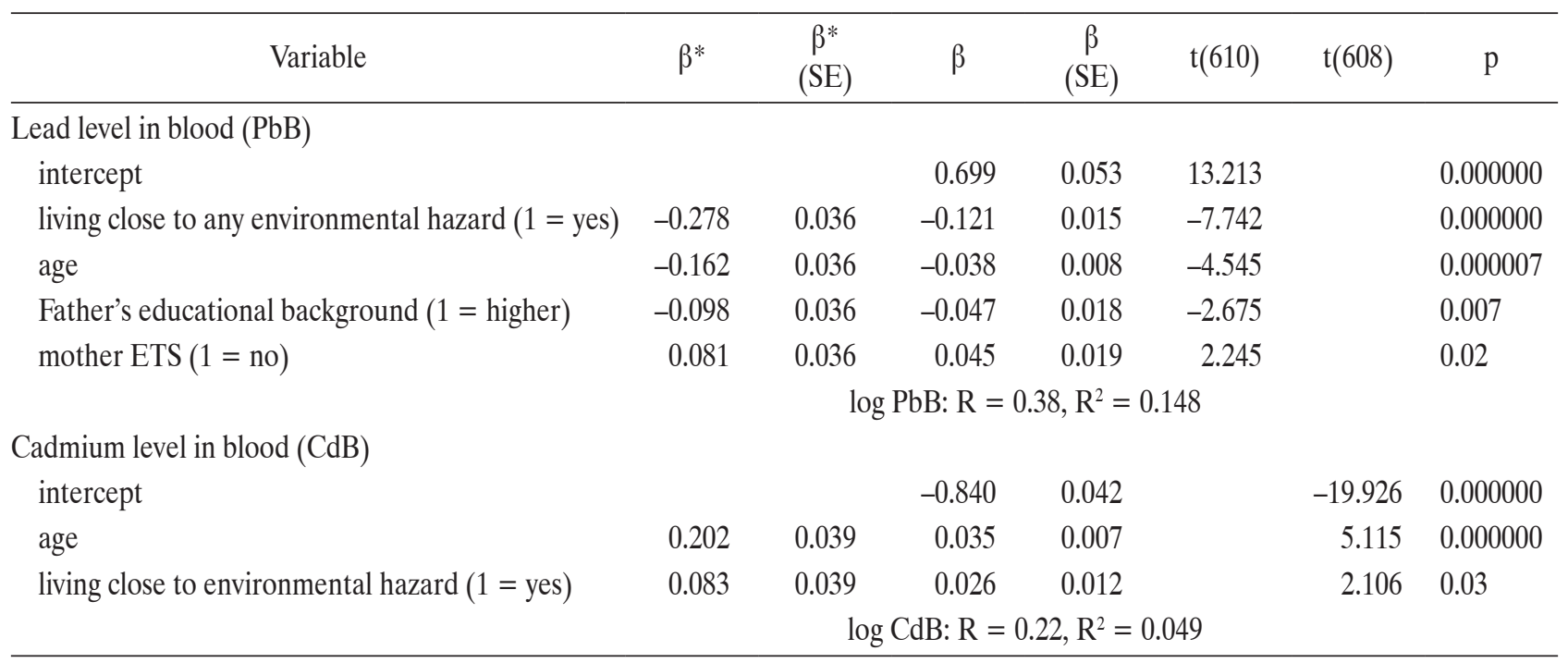

${ }^{a}$ Statistically significant impact on logarithm of both biomarkers.

ETS - environmental tobacco smoke; $\beta^{*}$ - standardized regression coefficient; $\beta$ - regression coefficient (slope); SE - standard error; $\mathrm{t}$ - test of regression coefficient significance; $\mathrm{R}$ - correlation coefficient; $\mathrm{R}^{2}$ - coefficient of determination.

trial plant and a busy road. Moreover, it has been noted that in the case of $68.2 \%$ of children, the level of lead in blood has exceeded the value of $2 \mu \mathrm{g} / \mathrm{dl}$, which means that we need to identify the source of risk in the environment of children.

\section{DISCUSSION}

Results of the study have confirmed that preschool children living in Piekary Śląskie are still exposed to heavy metals such as lead and cadmium. Soil remains the main source of exposure in the case of children population, and observed levels of biomarkers still exceed the permissible values of both pollutants. The highest risk has been documented for children living in the vicinity of metallurgical slag heaps located in Brzeziny district, this region has had the highest concentration of both pollutants in the soil [7] as well as levels of biomarkers in blood of children have been the highest. Moreover, a higher level of lead in blood has been related with the neighborhood of a gas station and an industrial plant. In the case of the cadmium bio- marker, the highest level has been detected for children living close to a car workshop, a busy road and an industrial plant. Our observation is consistent with well-known published data [3,9-11]. The vicinity of the source of environmental hazards is one of accepted methods of indirect measurement of exposure [12-14] and is often used in environmental epidemiology [15-17].

Irrespective of the information on the residence location, it is also important to determine the time which children spend outside in playgrounds. This kind of data is usually obtained while collecting parental opinions by means of the questionnaire. In our case, this approach has been used and we have also assessed the relationship between declared time spent outside and real level of biomarkers. Obtained results suggest that the concentration of both biomarkers has been significantly higher in the case of children spending more time outdoor in the colder season (winter). In the case of summer season, time spent outdoor has been significantly important only to lead in blood. Again must it be concluded that obtained results 
have confirmed the well-known relation between exposure and health effect [18].

Moreover, the parental questionnaire could be useful to the study of other sources of exposure in children's environment, especially in the situation in which we have no other individual data of measurement. Our observation has confirmed that apart from the place of residence, some circumferences such as: the parental level of education and any occupational contact with heavy metals as well as parental smoking at home could be important determinants for assessment of children's exposure. Obtained results are again similar to the aforementioned multicenter publication [19].

In the environmental epidemiology, direct and indirect methods of exposure assessment are generally used [12]. An indirect measure of exposure to heavy metals may be time spent in varied microenvironments (including children's activity outdoor), while the direct method involves measuring biological markers (such as $\mathrm{PbB}$ or $\mathrm{CdB}$ ). As demonstrated in our study, methods used for assessing exposure have given the similar effects as in the case of the data available in cited and well-known publications. The highest level of biomarkers has been detected for children who live in most polluted areas (close to a smelter heap, gasoline station, car workshop, industrial plants or a busy road) and additionally spend longer time outdoor. The percentage share of children from Piekary Śląskie in which the measured value exceeds $10 \mu \mathrm{g} / \mathrm{dl}$ for lead in venous blood has been $0.87 \%$, the hazard for cadmium is a bit lower - just for $0.8 \%$ of children, the measured concentration in blood has been higher than $0.5 \mu \mathrm{g} / \mathrm{l}$.

Our results are slightly worse than those observed in France, where $0.09 \%(0.03-0.15 \%)$ of children aged $<6$ years old have had $\mathrm{PbB}$ level greater than $10 \mu \mathrm{g} / \mathrm{dl}$ [20] or in the USA, where the percentage share of children in the same age with very high lead concentration $(\geq 10 \mu \mathrm{g} / \mathrm{dl})$ in venous blood has been $0.58 \%$ ( $0.61 \%$ of boys and $0.56 \%$ of girls) [21]. According to the recommendation, only $\mathrm{PbB}$ concentrations below $2 \mu \mathrm{g} / \mathrm{dl}$ are so safe that they do not require intervention, in the case of children with the level between $2 \mu \mathrm{g} / \mathrm{dl}$ and $5 \mu \mathrm{g} / \mathrm{dl}$, activities to assess the potential environmental sources of hazard in a child's environment should be implemented. In relation to children with concentrations above $10 \mu \mathrm{g} / \mathrm{dl}$, medical care should be implemented [6]. Obtained results suggest that for over 30\% children living in Piekary Śląskie, we need to control the level of this biomarker in future.

\section{CONCLUSIONS}

Obtained results have confirmed that preschool children living in Piekary Śląskie, Poland, are still exposed to heavy metals existing in environment. The parental questionnaire could be useful to identify potential determinants of exposure to lead and cadmium. It has been detected that a higher level of lead and cadmium biomarkers of exposure is related to children whose mothers smoke cigarettes in the presence of children, whose fathers are better educated and whose family live in the vicinity of environmental hazards. It must be unequivocally concluded that improvements of environment quality in Piekary Ślaskie are necessary to assure expected quality of health for children and we will continue local efforts to achieve the desired goals. It is especially important to continue education of parents and nursery teachers about the environmental hazard of heavy metals and proper behavior during normal life.

\section{REFERENCES}

1. Martuzzi M, Pasetto R, Martin-Olmedo P. Industrially contaminated sites and health. J Environ Public Health. 2014;198574, https://doi.org/10.1155/2014/198574.

2. International Society for Environmental Epidemiology [Internet]. Rome: The Society; 2016 [cited 2016 Nov 9]. COST Action IS1408 ICSHNet's Abstract - ISEE, 2016. Available from: http://www.icshnet.eu/news/abstract-isee2016.

3. Landrigan PJ, Garg A. Children are not little adults. In: Pronczuk-Garbino J, editor. Children's health and the environment. Geneva: World Health Organization; 2005. p. 3-15. 
4. Needleman HL, Schell A, Bellinger D, Leviton A, Allred EN. The long-term effects of exposure to low doses of lead in childhood. N Engl J Med. 1990;322(2):83-8, https:// doi.org/10.1056/NEJM199001113220203.

5. Strugała-Stawik H, Rudkowski Z, Pastuszek B, Morawiec K. [Biomonitoring of lead in blood of children - Short assessment of results 1991-2009]. Environ Med. 2010;13(3):11-4. Polish.

6. Gilbert SG, Weiss B. A rationale for lowering the blood lead action level from 10 to $2 \mu \mathrm{g} / \mathrm{dL}$. Neurotoxicology. 2006; 27(5):693-701, https://doi.org/10.1016/j.neuro.2006.06.008.

7. Kulka E, Gzyl J. Assessment of lead and cadmium soil contamination in the vicinity of a non-ferrous metal smelter. Arch Environ Prot. 2008;34(Special issue):105-15.

8. Centers for Disease Control and Prevention [Internet]. Atlanta: The Centers [cited 2016 Nov 9]. Biomonitoring summary lead and cadmium, 2015. Available from: http://www. cdc.gov/biomonitoring.

9. European Environment Agency. Environment and human health. Joint EEA-JRC report No. 5/2013. Report EUR 25933 [Internet]. Copenhagen: The Agency; 2013 [cited 2016 Nov 9]. Available from: https://doi.org/10.2800/9092.

10. Kovarik W. Ethyl-leaded gasoline: How a classic occupational disease became an international public health disaster. Int J Occup Environ Health. 2005;11(4):384-97, https:// doi.org/10.1179/oeh.2005.11.4.384.

11. Mielke HW, Reagan PL. Soil is an important pathway of human lead exposure. Environ Health Perspect. 1998;106 (Suppl 1):217-29.

12. Frumkin H, editor. Environmental health. From global to local. 3rd ed. San Francisco: Jossey-Bass; 2005. p. 57-91.

13. Järup L. Health Effects of exposure to metals from manufacturing plants. In: Briggs DJ, Stern RM, Tinker TL, editors. Environmental health for all risk assessment and risk communication for National Environmental Health Action Plans. Berlin: Kluwer Academic Publishers; 1999, p. 69-76.

14. Neuwenhuijsen MJ. Exposure assessment in occupational and environmental epidemiology. New York: Oxford University Press; 2003, p. 12-8.

15. Benin AL, Sargent JD, Dalton M, Roda S. High concentrations of heavy metals in neighborhoods near ore smelters in northern Mexico. Environ Health Perspect. 1999;107(4):279-84, https://doi.org/10.1289/ehp.99107279.

16. Farrell KP, Brophy MC, Chisolm JJ, Rohde CA, Strauss WJ. Soil lead abatement and children's blood lead levels in an urban setting. Am J Public Health. 1998;88(12):1837-9, https://doi.org/10.2105/AJPH.88.12.1837.

17. Wilhelm M, Eberwein G, Hölzer J, Gladtke D, Angerer J, Marczynski B, et al. Influence of industrial sources on children's health - Hot spot studies in North Rhine Westphalia, Germany. Int J Hyg Environ Health. 2007;210(5):591-9, https://doi.org/10.1016/j.ijheh.2007.02.007.

18. Laidlaw MAS, Filippelli GM, Sadler RC, Gonzales CR, Ball AS, Mielke HW. Children's blood lead seasonality in flint, Michigan (USA), and soil-sourced lead hazard risks. Int J Environ Res Public Health. 2016;13(4):358, https://doi. org/10.3390/ijerph13040358.

19. Berglund M, Larsson K, Grandér M, Casteleyn L, KolossaGehring M, Schwedler G, et al. Exposure determinants of cadmium in European mothers and their children. Environ Res. 2015;141:69-76, https://doi.org/10.1016/j.envres.2014.09.042.

20. Etchevers A, Bretin P, Lecoffre C, Bidondo ML, Le Strat Y, Glorennec P, et al. Blood lead levels and risk factors in young children in France, 2008-2009. Int J Hyg Environ Health. 2014; 217(4-5):528-37, https://doi.org/10.1016/j.ijheh.2013.10.002.

21. McClure LF, Niles JK, Kaufman HW. Blood lead levels in young children: US, 2009-2015. J Pediatr. 2016;175:173-81, https://doi.org/10.1016/j.jpeds.2016.05.005.

This work is available in Open Access model and licensed under a Creative Commons Attribution-NonCommercial 3.0 Poland License - http://creativecommons.org/ licenses/by-nc/3.0/pl/deed.en. 